\title{
Estuarine Mysids in Sri Lanka: Implications for Conservation
}

\author{
N.N. Punchihewa \\ Department of Zoology, The Open University, Nawala, Sri Lanka \\ nnpun@ou.ac.lk
}

\begin{abstract}
Mysids are important fauna in estuarine hyperbenthic communities and have been reported to be an important component of the diet of many juvenile fish species in the estuarine waters. There is limited of information on the distribution of this important fauna in Sri Lankan estuarine waters and mysids are not included in biodiversity lists. Present study was conducted to record the mysid species inhabit in the estuarine systems from western and north-western region of Sri Lanka as a novel study. Surveys were undertaken from southwest to north-west coastal region of Sri Lanka starting from March 2012 to July 2013. From this study, four species of mysids were identified, i.e., Mesopodopsis zeylanica, M. orientalis, possibly new Siriella sp. and Anisomysis sp. mysids were found only in western and northwestern regions of Sri Lanka within nine major estuarine bodies. Number of species and their abundance recorded vary with different estuarine waters. It was noted that mysid habitats are very specific and they were absent from the sites where estuarine boundary without or limited riparian vegetations. Future management measures will be required to protect this important estuarine fauna in Sri Lanka.
\end{abstract}

Keywords: Riparian vegetation, Mysids, Estuarine fauna 